\title{
MYC quantitation in cell-free plasma DNA by real-time PCR for gastric cancer diagnosis
}

\author{
Kyoung Un Park', Hee Eun Lee ${ }^{2}$, Do Joong \\ Park $^{3}$, Eun Ji Jung ${ }^{4}$, Junghan Song ${ }^{1}$, Hyung-Ho \\ $\mathrm{Kim}^{3}$, Gheeyoung $\mathrm{Choe}^{2}$, Woo Ho $\mathrm{Kim}^{4}$ and \\ Hye Seung Lee Le* $^{2, *}$ \\ ${ }^{1}$ Department of Laboratory Medicine, Seoul \\ National University Bundang Hospital, Seongnam, \\ Korea \\ 2 Department of Pathology, Seoul National \\ University Bundang Hospital, Seongnam, Korea \\ ${ }^{3}$ Department of Surgery, Seoul National University \\ Bundang Hospital, Seongnam, Korea \\ ${ }^{4}$ Department of Pathology, Seoul National \\ University College of Medicine, Seoul, Korea
}

\begin{abstract}
Background: Detection of tumor-associated genetic alterations in plasma of cancer patients has recently been suggested to be an accurate method for detecting early or recurrent cancer.

Methods: We performed quantitative real-time PCR for $M Y C$ and GAPDH in tissue and plasma samples of 57 patients with gastric cancer and in plasma of 79 cancer-free individuals. We also performed two-color $M Y C$ fluorescence in situ hybridization (FISH) in tissue from the 57 patients with gastric cancer.

Results: The tissue $M Y C / G A P D H$ ratio by real-time PCR was significantly correlated with $M Y C$ status by FISH $(p<0.001)$. The mean ratio of plasma MYC/ GAPDH was $5.226 \pm 3.578$ (range: $1.25-18.35$ ) in gastric cancer patients, and $2.436 \pm 0.881$ (range: 1.00 $5.00)$ in the healthy volunteers $(p<0.001)$. We used receiver-operating characteristics (ROC) curve analysis to select two optimal plasma MYC/GAPDH cut-offs of 2.725 and 5.225 . The sensitivity and specificity were $75.4 \%$ and $76.9 \%$ at $2.725,38.6 \%$ and $100 \%$ at 5.225 , respectively. The plasma MYC/GAPDH ratio from cancer patients was significantly correlated with the tissue $M Y C / G A P D H$ ratio $(p=0.009)$, and tissue $M Y C$ status by FISH $(p=0.024)$.

Conclusions: These findings suggest that the plasma $M Y C / G A P D H$ ratio, as determined by real-time PCR, may be an alternative non-invasive approach for detecting gastric cancer.

Clin Chem Lab Med 2009;47:530-6.
\end{abstract}

Keywords: $M Y C$; plasma DNA; real-time PCR; stomach cancer.

*Corresponding author: Hye Seung Lee, MD, Department of Pathology, Seoul National University Bundang Hospital, 300 Gumi-dong, Bundang-gu, Seongnam-si, Gyeonggi-do, 463-707, Korea

Phone: +82-31-787-7714, Fax: +82-31-787-4012,

E-mail: hye2@snu.ac.kr

Received December 25, 2008; accepted February 9, 2009; previously published online March 23, 2009

\section{Introduction}

Gene amplification and deletion plays an important role in the pathogenesis of solid tumors. The MYC gene is a known oncogene that encodes a transcription factor that plays an essential role in cell proliferation, cell growth, differentiation and apoptosis (1). Oncogenic alterations in $M Y C$ are induced by events such as point mutations, gene amplification, translocation, over expression, enhanced translation and increased protein stability. The most common MYC aberration in solid tumors is gene amplification (2). It is possible to detect $M Y C$ amplification by southern blotting, fluorescence in situ hybridization (FISH), chromogenic in situ hybridization and quantitative PCR. FISH has been universally accepted as the standard method for detection of gene amplification, and amplification of $M Y C$ was found by FISH in 15\%-30\% of gastric cancers (3-6). Real-time PCR is a new method for quantitative DNA analysis, and has been reported to be a highly reproducible method for determining gene amplification, including HER-2 and MYC status $(7,8)$.

Gastric cancer is the fourth most common cancer and the second leading cause of cancer deaths worldwide $(9,10)$. Curative resection is the most effective treatment for gastric cancer, and the 5-year survival rate is more than $90 \%$ when gastric cancer is detected early. However, more than $50 \%$ of gastric cancer patients with advanced stage will die of recurrent or metastatic disease $(11,12)$. Earlier detection of gastric cancer would improve the efficacy of treatment and disease management. Thus, it is necessary to identify and develop reliable diagnostic markers for early detection of gastric cancer. Detectable tumor-associated DNA sequences have been demonstrated in the plasma of cancer patients (13). Thus, it has been possible to identify tumor-specific microsatellite alteration, ras gene mutations, and promoter methylation in the serum and/or plasma DNA of patients with different cancers (14-16). Using Epstein-Barr virus (EBV) DNA as the target genome, circulating EBV DNA has been shown to be a useful tumor marker for EBV-positive gastric cancers. This suggests the presence of circulating tumor-associated DNA in gastric cancer patients (17). Measurement of serum MYCN status using DNA-based real-time PCR has recently been reported to be an accurate method for assessing MYCN status in patients with neuroblastoma (18).

In this study, in order to demonstrate tumor-associated DNA in the plasma of gastric cancer patients, we performed quantitative real-time PCR for $M Y C$ and a reference gene in tissue and plasma samples of 57 patients with gastric cancer. We also performed measurements in the plasma of 79 cancer-free indi- 
viduals. In addition, we performed two-color FISH in the tissue samples of 57 cases of surgically resected primary gastric cancer.

\section{Materials and methods}

\section{Case selection}

A total of 86 patients with gastric cancer underwent gastric resection at Seoul National University Bundang Hospital between January and April, 2005. We obtained the matching cell-free plasma samples of these same patients by collecting remnants of pre-operative blood samples. Using this technique, we obtained 57 cases $(66.3 \%)$ of gastric cancer tissue and matching cell-free plasma samples. Thirty-eight males and 19 females with a mean age $( \pm S D)$ of $61.3 \pm 11.3$ years were included. Depth of invasion and lymph node metastasis was evaluated following review of the pathology records (12). Thirty-two cases of early gastric cancer and 25 advanced cancers were represented. Tissue slides were reviewed for histologic classifications according to the WHO and Lauren's classifications $(11,19)$. For the plasma samples of disease-free controls, 39 anonymous age-matched healthy volunteers were enrolled. They did not have any neoplasm in their stomach or other organs.

In addition to the samples from gastric cancer patients and healthy controls, we collected cell-free plasma samples from patients with gastric adenoma and those with gastritis. Blood samples from four patients with gastric adenoma were collected using remnants of preoperative blood samples before endoscopic mucosal resection. All adenomas were low-grade tubular adenomas without cancerous transformation in any focus. Thirty-six patients with gastritis who underwent routine gastroscopy and routine blood tests were also enrolled. Of these patients with gastritis, ten were infected with Helicobacter pylori, and nine patients had intestinal metaplasia by histologic findings. Patients with gastritis did not have any neoplasm in their stomach or other organs.

For the positive $M Y C$ amplification control, we used the gastric cancer cell line, SNU16, which has been reported to have MYC amplification (20). This study was approved by the institutional Review Board for human subject research at Seoul National University Bundang Hospital.

\section{Tissue array method}

A tissue array block containing a total of 57 cases was prepared as described previously (Superbiochips Laboratories, Seoul, Korea) (21). A core tissue biopsy, $2 \mathrm{~mm}$ in diameter, was taken from an individual paraffin-embedded gastric tumor (donor block) and arranged in a recipient paraffin block (tissue array block) using a trephine. Cases were considered adequate if tumor occupied more than $10 \%$ of the core area. Four $\mu \mathrm{m}$ sections were cut from each tissue array block, deparaffinized, and then dehydrated.

\section{FISH analysis}

Two-color FISH of tumor interphase nuclei was performed using the LSI MYC (8q24.12-q24.13) and CEP8 probes (Vysis, Downers Grove, IL, USA). The MYC specific locus probe was labeled in orange, the chromosome eight centromere was labeled in green, and the nuclei were counterstained in blue (DAPI, Vysis, Downers Grove, IL, USA). The fluorescent signals were counted in $2 \times 20$ non-overlapping nuclei per tissue array core. The ratio between the $M Y C$ signals and the chromosome eight centromere signals was established; (i) 'high amplification' was considered to occur when this ratio was $\geq 2$ : (ii) more than two signals accompanied by an identical number of centromere signals in more than $60 \%$ of tumor cells was considered 'low amplification (polysomy)': and (iii) only two gene signals in more than $60 \%$ of the tumor cells were scored as 'non-amplified MYC (disomy)' $(22,23)$.

\section{DNA extraction from tissue and plasma samples}

DNA from tissue of 57 patients with primary gastric cancer was obtained after manual microdissection with hematoxylin-eosin stained sections of the formalin-fixed, paraffin embedded surgical specimens. This microdissection procedure enabled more than $60 \%$ purity of the tumor cell populations to be obtained. The DNA was extracted using a chelating ion exchange resin (InstaGene Matrix, Bio-Rad, Hercules, CA, USA).

The plasma from 57 patients with gastric cancer, four patients with gastric adenoma, 36 with gastritis, and 39 healthy persons was treated by filtration (Fisher Scientific, Pittsburgh, PA, USA), and the plasma DNA was extracted using a High Pure Viral Nucleic Acid kit (Roche, Penzberg, Germany). The plasma DNA was extracted from all 57 plasma samples from patients with gastric cancer.

\section{Real-time PCR analysis for relative gene copy number quantification}

Real-time quantitative TaqMan PCR was performed on each sample using a Universal ProbeLibrary (UPL) (Roche) and LightCycler 2.0 (Roche). In addition, to the MYC gene, GAPDH was simultaneously measured as a reference gene. The primer sets used were as follows: $M Y C$ forward, $5^{\prime}-C C T$ CCC TCC ACT CGG AAG-3'; MYC reverse, 5'-TCT GAC ACT GTC CAA CTT GAC C-3'; GAPDH forward, 5'-ACA CCC ACT CCT CCA CCT TT-3'; GAPDH reverse, 5'-TGA CAA AGT GGT CGT TGA GG-3' (Bioneer, Daejeon, Korea). The UPL probe sequences were as follows: MYC (UPL 18), 5'-tcc tgc tg-3'; GAPDH (UPL 45), 5'-ctg ggg ct-3'. All the reactions were performed in a final volume of $20 \mu \mathrm{L}$ that contained $5 \times$ LightCycler TaqMan Master $4 \mu \mathrm{L}$ (Roche), UPL probe $0.4 \mu \mathrm{L}$, each primer $0.4 \mu \mathrm{L}$, and DNA $5 \mu \mathrm{L}$. All reactions were performed using the same cycling conditions: $95^{\circ} \mathrm{C}$ for $10 \mathrm{~s}$, $55^{\circ} \mathrm{C}$ for $30 \mathrm{~s}$, and $72^{\circ} \mathrm{C}$ for $1 \mathrm{~min}$, for 45 cycles.

For each run, five dilutions of DNA of the stomach cancer cell line (SNU16), which harbors a high-level MYC amplification, were used to generate a gene-specific internal calibration curve. Real-time PCR amplification efficiencies $(E)$ were determined according to the equation: $E=10^{(-1 / \text { slope })}$. As a modification of the $2^{-\triangle \Delta C T}$ method (24), we calculated the relative gene copy number (termed MYC/GAPDH ratio) in the test sample from the PCR efficiencies. These were determined for each run, and the crossing point (CP) deviations of the target and reference genes in a control vs. a test

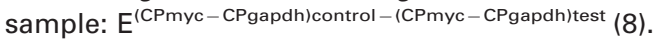

\section{Statistical analysis}

Patients with gastric cancer and cancer-free individuals were compared with respect to plasma $M Y C / G A P D H$ ratio by the independent t-test. The plasma $M Y C / G A P D H$ ratio was evaluated using receiver-operating characteristic (ROC) curve analysis and the area under the ROC curve (AUC) used for statistical comparisons. Correlation coefficients between the plasma $M Y C / G A P D H$ ratio and the clinicopathologic factors were estimated by Pearson's correlation analysis. Results were considered to be statistically significant at $p<0.05$. All 
statistical analyses were conducted using SPSS 15.0 statistical software program (SPSS, Chicago, IL, USA).

\section{Results}

MYC status by FISH and real-time quantitative PCR in gastric cancer tissues

Of the 57 gastric cancer tissues, high amplification of MYC gene was found in seven specimens $(12.3 \%)$ by FISH, and low amplification of MYC in 21 (36.8\%) (Figure 1). Gastric cancers with high amplification and low amplification of $M Y C$ had a tendency to be the intestinal type, according to Lauren's classification $(p=0.012)$ (Table 1).

Real-time quantitative PCR was performed on seven gastric cancer tissue samples with high amplifi- cation of $M Y C, 21$ cancer tissue samples with low amplification, and 29 cancer tissues with non-amplified $M Y C$ (Figure 1). The $M Y C / G A P D H$ ratio in gastric cancer tissues with high amplification was significantly higher than the ratio seen in cancer tissues with low amplification and non-amplified MYC (Table 2 ). The ROC curve was obtained by comparing the tissues with high amplification, low amplification and non-amplified MYC. The optimized MYC/GAPDH ratio for $M Y C$ amplification in gastric cancer tissue was 9.5 ( $100 \%$ sensitivity and $100 \%$ specificity).

\section{MYC status in cell-free plasma DNA of gastric cancer patients and controls}

In plasma samples collected from 57 gastric cancer patients prior to surgery and from 79 individuals who
A
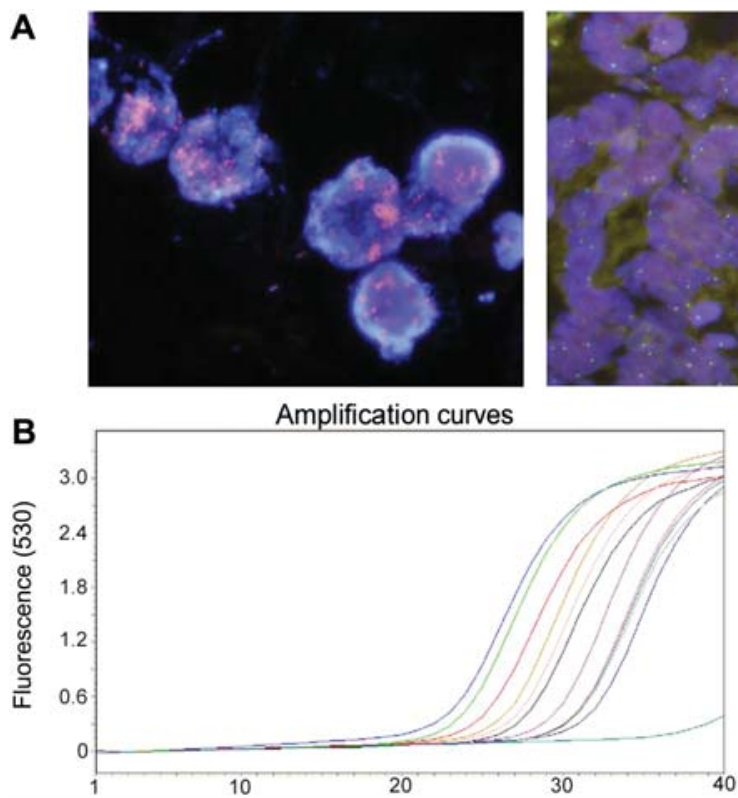
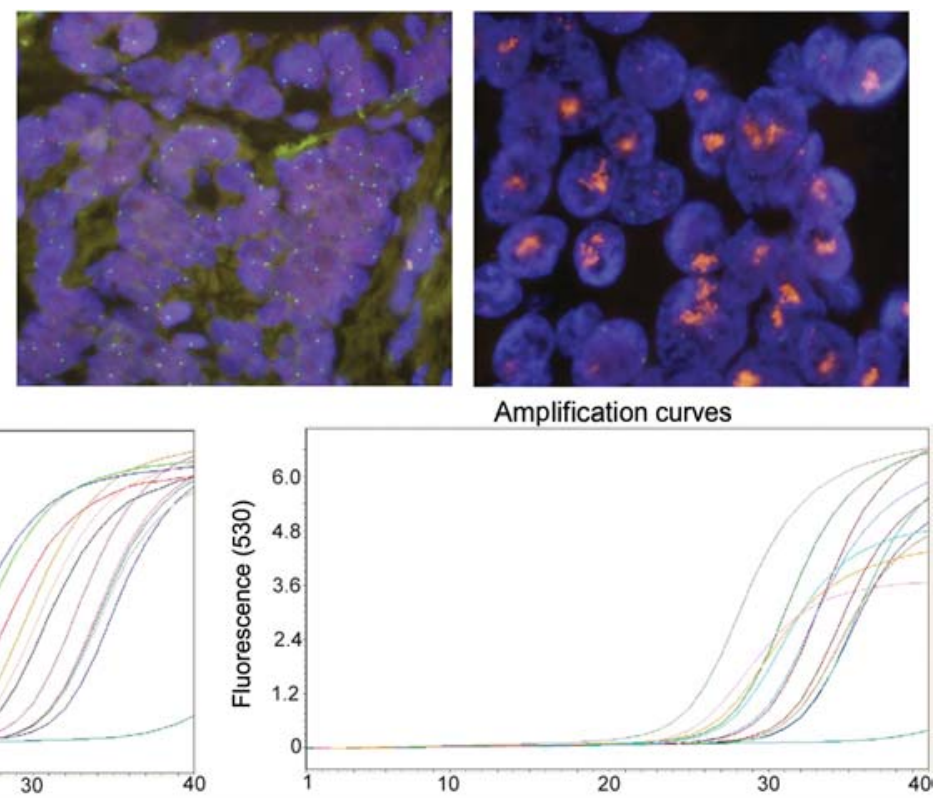

Figure 1 MYC status by FISH and quantitative real-time PCR.

(A) MYC status by FISH analysis $(\times 400)$; the gastric cancer cell-line (SNU16) as the positive control (left), non-amplified gastric cancer (center), and highly amplified gastric cancer (right). (B) Amplification curves of MYC (left) and GAPDH (right) by quantitative real-time PCR.

Table 1 Correlation between MYC status of gastric cancer tissue, determined by FISH, and clinicopathologic parameters.

\begin{tabular}{|c|c|c|c|c|c|}
\hline & \multicolumn{3}{|c|}{$M Y C$ status by FISH } & \multirow[t]{2}{*}{ Total } & \multirow[t]{2}{*}{ p-Value } \\
\hline & $\begin{array}{l}\text { Non- } \\
\text { amplified }\end{array}$ & $\begin{array}{l}\text { Low } \\
\text { amplification }\end{array}$ & $\begin{array}{l}\text { High } \\
\text { amplification }\end{array}$ & & \\
\hline Age & $57.28 \pm 13.09$ & $64.76 \pm 7.654$ & $67.43 \pm 6.133$ & $61.28 \pm 11.32$ & 0.019 \\
\hline Tumor size & $4.886 \pm 3.752$ & $4.600 \pm 3.289$ & $3.543 \pm 2.351$ & $4.616 \pm 3.417$ & NS \\
\hline \multicolumn{6}{|l|}{ Lauren classification } \\
\hline Intestinal & 9 & 13 & 6 & 28 & \multirow[t]{2}{*}{0.012} \\
\hline Diffuse & 20 & 8 & 1 & 29 & \\
\hline \multicolumn{6}{|l|}{ Tumor progression } \\
\hline Early gastric cancer (EGC) & 15 & 13 & 4 & 32 & \multirow[t]{2}{*}{ NS } \\
\hline Advanced gastric cancer (AGC) & 14 & 8 & 3 & 25 & \\
\hline \multicolumn{6}{|l|}{ Lymph node metastasis } \\
\hline Absent & 15 & 12 & 6 & 33 & \multirow[t]{3}{*}{ NS } \\
\hline Present & 14 & 9 & 1 & 24 & \\
\hline Total & 29 & 21 & 7 & 57 & \\
\hline
\end{tabular}

NS, not significant $(p>0.05)$. FISH, fluorescence in situ hybridization. 
Table 2 The tissue $M Y C / G A P D H$ ratio, measured by quantitative real-time PCR, in $M Y C$-amplified and non-amplified gastric cancer using FISH.

\begin{tabular}{lll}
\hline FISH & $\mathrm{n} \quad \begin{array}{l}\text { Mean ratio of tissue } \\
M Y C / G A P D H\end{array}$ & $\mathrm{p}$-Value
\end{tabular}

Non-amplified $293.541 \pm 1.804(1.10-7.60)$

Low amplification $21 \quad 5.124 \pm 1.975(2.40-9.00) \quad<0.001$

High amplification $7 \quad 11.83 \pm 1.267(10.00-13.20)$

FISH, fluorescence in situ hybridization.

were cancer-free (four gastric adenoma patients, 36 gastritis patients, and 39 healthy volunteers), the mean ratio of plasma $M Y C / G A P D H$ determined by real-time PCR was 5.226 \pm 3.578 (range: $1.25-18.35$ ) in the patients with gastric cancer, $2.436 \pm 0.881$ (range: $1.00-5.00)$ in the healthy volunteers, $2.550 \pm 1.162$ (range: $0.50-5.40$ ) in patients with gastritis, and $2.800 \pm 0.356$ (range: 2.30-3.10) in patients with adenoma. The mean ratio of plasma $M Y C / G A P D H$ between patients with gastric cancer and cancer-free individuals was statistically significant $(p<0.001)$. The mean ratio of plasma MYC/GAPDH was $5.791 \pm 4.195$ (range: 1.55-18.35) in patients with early gastric cancer, and $4.504 \pm 2.485$ (range: $1.25-11.50$ ) in plasma of patients with advanced cancer $(p>0.05)$ (Figure 2).

The ROC curve for the ratio of plasma MYC/GAPDH was obtained by comparing the gastric cancer patients and age-matched healthy volunteers (Figure 2). The ROC curve showed that classification using the plasma $M Y C / G A P D H$ ratio had significant discriminating ability to differentiate gastric cancer patients from healthy controls. We selected two cut-offs of the plasma $M Y C / G A P D H$ ratio of 2.725 and 5.225 . The sensitivity and specificity were $75.4 \%$ and $76.9 \%$ at a 2.725 cut-off value and $38.6 \%$ and $100 \%$ at a 5.225 cutoff value, respectively (Table 3). Twenty-two (38.6\%) of 57 patients with gastric cancer had an elevated
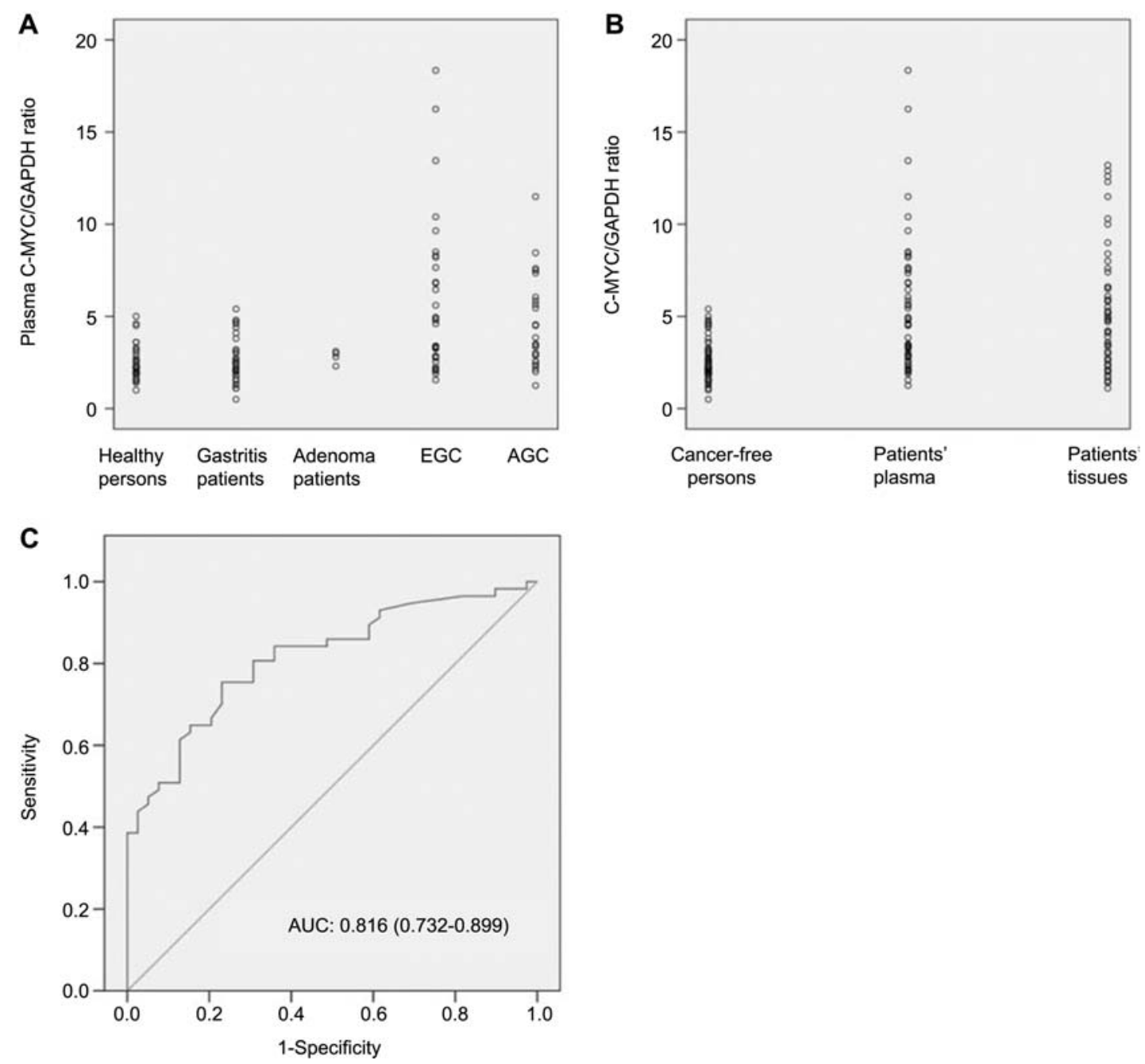

Figure 2 Scatter plots and receiver-operating characteristics (ROC) curve.

(A) Scatter plot of the plasma MYC/GAPDH ratio as determined by real-time PCR for the 39 healthy volunteers, 36 gastritis patients, four adenoma patients, 32 early gastric cancer patients, and 25 advanced cancer patients. (B) Scatter plot of the MYC/GAPDH ratio as determined by real-time PCR for the plasma samples of the 79 cancer-free individuals (left), for the plasma samples of the 57 gastric cancer patients (center), and for the tissue samples of the 57 cancer patients (right). (C) ROC curve obtained by comparing the cell-free plasma ratio of $M Y C / G A P D H$ between the 57 gastric cancer patients and 39 healthy controls. EGC, early gastric cancer; AGC, advanced gastric cancer; AUC, area under the ROC curve. 
Table 3 Sensitivity and specificity for diagnosis of gastric cancer using the plasma $M Y C / G A P D H$ ratio at two different cut-off values.

\begin{tabular}{lllll}
\hline Cut-off & $\begin{array}{l}\text { Sensitivity, } \\
\%\end{array}$ & $\begin{array}{l}\text { Specificity, } \\
\%\end{array}$ & $\begin{array}{l}\text { PPV, } \\
\%\end{array}$ & $\begin{array}{l}\text { NPV, } \\
\%\end{array}$ \\
\hline 2.725 & 75.4 & 76.9 & 82.7 & 68.2 \\
5.225 & 38.6 & 100 & 100 & 52.7 \\
\hline
\end{tabular}

Cut-off, cut-off value of plasma MYC/GAPDH ratio; PPV, positive predictive value; NPV, negative predictive value.

plasma MYC/GAPDH ratio using the cut-off of 5.225 . These 22 patients consisted of 13 with early gastric cancer and nine with advanced cancer $(p=0.722)$.

\section{Correlation between plasma $M Y C$ status and clinicopathologic characteristics}

Table 4 shows the correlation coefficients between the various clinicopathologic factors and the plasma $M Y C / G A P D H$ ratio in patients with cancer. For factors such as age, tumor size, depth, metastasis, histologic type, and the tissue $M Y C / G A P D H$ ratio, the plasma $M Y C / G A P D H$ ratio from the cancer patients was significantly correlated with the tissue $M Y C / G A P D H$ ratio $(p=0.009)$ and the tissue $M Y C$ status by FISH $(p=0.024)$. The mean ratio of plasma $M Y C / G A P D H$ in patients with non-amplified $M Y C(4.159 \pm 2.553)$ by FISH was lower than in patients with low amplification (6.024 \pm 4.029$)$ and those with high amplification of $M Y C(7.257 \pm 4.736)(p=0.016)$.

Evaluation of the two cut-offs of the plasma $M Y C /$ $G A P D H$ ratio between gastric cancer patients and healthy volunteers showed that the mean ratio of tissue $M Y C / G A P D H$ in cancer patients with a plasma $M Y C / G A P D H$ ratio above 2.725 was $5.665 \pm 3.366$. The mean ratio of tissue $M Y C / G A P D H$ in the patients with a plasma $M Y C / G A P D H$ ratio below 2.725 was $3.536 \pm$ $1.805(\mathrm{p}=0.028)$. The mean ratio of tissue $M Y C /$ GAPDH in cancer patients with a plasma MYC/GAPDH ratio above 5.225 was $6.350 \pm 2.872$, and the mean ratio of tissue $M Y C / G A P D H$ in patients with a plasma MYC/GAPDH ratio below 5.225 was $4.383 \pm 3.165$ $(\mathrm{p}=0.022)$. Evaluating the two cut-offs $(2.725$ and 5.225) showed that the plasma MYC/GAPDH ratio did not show any correlation with tumor size, depth, lymph node metastasis, and angiolymphatic invasion of gastric cancers $(p>0.05)$ (data not shown).

The plasma $M Y C / G A P D H$ ratio was not correlated with age of individuals that were cancer-free $(r=-0.10, p=0.381)$. For the 36 patients with gastritis, the plasma $M Y C / G A P D H$ ratio did not show significant correlation with $H$. pylori infection status $(r=-0.005, \quad p=0.975)$ or intestinal metaplasia $(r=-0.160, p=0.353)$.

\section{Discussion}

Gastroscopy with biopsy, plasma carcinoembryonic antigen (CEA) concentrations, and computed tomography (CT) have all been used for making the diagnosis of gastric cancer. Early gastric cancer cannot be easily diagnosed by plasma CEA concentrations or CT due to their low sensitivity, and detecting early gastric cancer by gastroscopy is dependent on the skill and experience of the physician. While the 5-year survival rate is more than $90 \%$ for patients detected early with gastric cancer, more than $50 \%$ of patients with advanced-stage gastric cancer will die of recurrent or metastatic disease $(11,12)$. There are no additional helpful diagnostic methods to help detect recurrence of disease. Therefore, new diagnostic methods for detecting early gastric cancer and disease recurrence are needed. This study showed that higher levels of the $M Y C / G A P D H$ ratio in cell-free plasma DNA could be detected using real-time PCR in gastric cancer patients, compared with cancer-free controls. We suggest that plasma $M Y C$ status can be used as a new approach for detecting gastric cancer.

Tumor-specific DNA has been detected in the plasma of patients with cancer of the lung, head and neck, breast, colon, and gastric cancer (13-18). This suggests that cell-free plasma is a good source for detecting cancer-specific DNA markers. The plasma DNA concentrations in patients with gastric cancer were recently reported to be significantly higher than those of the control group, and the DNA integrity was also higher in cancer patients than that of the controls (25). DNA methylation status including $p 16$ and $p 15$, and the detection of EBV DNA, have been used for the

Table 4 Correlation coefficients between the $M Y C / G A P D H$ ratio in the cell-free plasma DNA and clinicopathologic parameters.

\begin{tabular}{lcc}
\hline Parameters & \multicolumn{1}{c}{ Plasma $M Y C / G A P D H$ ratio } \\
\cline { 2 - 3 } & Correlation coefficient & p-Value \\
\hline Tissue MYC/GAPDH ratio by real-time PCR & 0.342 & $0.09^{\text {a }}$ \\
Tissue MYC status by FISH & 0.240 & $0.024^{\text {b }}$ \\
Age & 0.008 & 0.955 \\
Lauren classification & -0.051 & 0.706 \\
Size & -0.015 & 0.912 \\
Depth of invasion & -0.099 & 0.029 \\
Lymph node metastasis & -0.144 \\
Lymphatic invasion & -0.079 \\
Venous invasion & 0.105 \\
Cancer border & 0.285 \\
\hline
\end{tabular}

${ }^{\mathrm{a}} \mathrm{p}<0.01 ;{ }^{\mathrm{b}} \mathrm{p}<0.05$. FISH, fluorescence in situ hybridization. 
early detection of tumor-related DNA in the serum or plasma of patients with gastric cancer $(17,26)$. Tumorspecific microsatellite alterations and mutations in the serum and/or plasma DNA of patients with different cancers has been reported (14-16). We demonstrated $M Y C$ amplification in the filtered plasma of gastric cancer patients using real-time PCR. Thus, MYC amplification in the plasma DNA may be used for detecting gastric cancer. Other amplified genes in plasma of gastric cancer patients includes C-MET, $k$-sam, and HER-2. These may be candidates for use in detection of gastric cancer.

We developed ROC curves by comparing the plasma MYC/GAPDH ratio between gastric cancer patients and healthy volunteers. We selected two $M Y C / G A P D H$ cut-offs of 2.725 and 5.225. At the cutoff of 5.225 , the specificity and positive predictive value were high $(100 \%)$, but the sensitivity was low $(38.6 \%)$. Of the 22 gastric cancer patients with a plasma $M Y C / G A P D H$ ratio above $5.225,13$ patients had early gastric cancer $(\mathrm{p}>0.05)$. In addition, the plasma $M Y C / G A P D H$ ratio in gastric cancer patients was not correlated with invasion depth, lymph node metastasis or angiolymphatic invasion $(p>0.05)$. We suggest that early gastric cancer can be detected by the plasma MYC/GAPDH ratio.

In this study, the plasma $M Y C / G A P D H$ ratio was correlated with the tissue $M Y C / G A P D H$ ratio (correlation coefficient: $0.342, \mathrm{p}=0.009)$, and tissue $M Y C$ status as determined by FISH (correlation coefficient: $0.240, p=0.024)$. However, correlation coefficients were relatively low suggesting that plasma MYC status is roughly correlated with the tissue MYC status in gastric cancer patients. There are a number of possible reasons for this, including tumor volume, angiogenesis capacity, and tumor apoptosis/necrosis. In this study, tumor size, depth, and lymph node metastasis were not significantly correlated with the plasma MYC/GAPDH ratio. Therefore, the physiological characteristics of the tumor including angiogenesis and apoptosis/necrosis may be more important for predicting plasma $M Y C$ status compared with tumor size or extent. In addition, the quantity and quality of the DNA template extracted from plasma is likely to differ from the quality of the original tumor tissue, based on the time of collection, the content of DNase, and other factors. The amount of DNA template derived from normal proliferative/apoptotic cells is also likely to be variable amongst patient plasma, and may be another important reason for the results obtained.

We performed real-time PCR for determining the $M Y C$ status in gastric cancer tissue and we compared it with the results of the FISH findings. The tissue $M Y C / G A P D H$ ratio in cases with high amplification of $M Y C$ by FISH was significantly higher than the tissue $M Y C / G A P D H$ ratio in both the non-amplified cases and low amplification cases. This result is generally consistent with previous studies showing some gene amplification in various tumors (7, 8, 27). Thus, although FISH remains a standard method for determining gene amplification status, real-time PCR may be an alternative to FISH for determining MYC status.
Various genetic alterations have been reported to correlate with aggressive and invasive features in gastric cancer, and many genetic alterations are frequently found in advanced gastric cancer. Genetic changes, found in both early and advanced gastric cancer, could be helpful for early detection of gastric cancer. The $M Y C$ alteration has been found in both early and advanced gastric cancer in previous studies (5), as well as this study. Therefore, MYC alterations may be a good candidate for diagnosing gastric cancer. Other studies have shown an association between $M Y C$ amplification and clinicopathologic features of gastric cancer. Calcagno et al. demonstrated $M Y C$ amplification in intestinal types of gastric cancer by FISH (6). In this study, cases with high amplification and low amplification had a higher tendency of the intestinal type, supporting previous results.

In summary, we performed quantitative real-time PCR on tissue and plasma of 57 patients with gastric cancer, and on plasma of 79 individuals that were cancer-free in order to determine MYC status. The plasma MYC/GAPDH ratio in the gastric cancer patients was significantly higher than the plasma $M Y C / G A P D H$ ratio in the healthy controls. The $M Y C /$ $G A P D H$ ratio in cell-free plasma DNA, as determined by real-time PCR, may be an alternative non-invasive approach for the detection of gastric cancer. The plasma $M Y C / G A P D H$ ratio from cancer patients was significantly correlated with the ratio of $M Y C / G A P D H$ in cancer tissue.

\section{Acknowledgements}

This study was supported by grant no. 02-2006-044 from the Seoul National University Bundang Hospital Research Fund.

\section{References}

1. Henriksson M, Luscher B. Proteins of the Myc network: essential regulators of cell growth and differentiation. Adv Cancer Res 1996;68:109-82.

2. Vita M, Henriksson M. The Myc oncoprotein as a therapeutic target for human cancer. Semin Cancer Biol 2006; 16:318-30.

3. Koo SH, Kwon KC, Shin SY, Jeon YM, Park JW, Kim SH, et al. Genetic alterations of gastric cancer: comparative genomic hybridization and fluorescence in situ hybridization studies. Cancer Genet Cytogenet 2000;117:97103.

4. Hara T, Ooi A, Kobayashi M, Mai M, Yanagihara K, Nakanishi I. Amplification of MYC, K-sam, and c-met in gastric cancers: detection by fluorescence in situ hybridization. Lab Invest 1998;78:1143-53.

5. Suzuki S, Tenjin T, Watanabe H, Matsushima S, Shibuya $\mathrm{T}$, Tanaka S. Low level c-myc gene amplification in gastric cancer detected by dual color fluorescence in situ hybridization analysis. J Surg Oncol 1997;66:173-8.

6. Calcagno DQ, Leal MF, Taken SS, Assumpção PP, Demachki S, Smith Mde A, et al. Aneuploidy of chromosome 8 and C-MYC amplification in individuals from northern Brazil with gastric adenocarcinoma. Anticancer Res 2005;25:4069-74. 
7. Tse C, Brault D, Gligorov J, Antoine M, Neumann R, Lotz $J P$, et al. Evaluation of the quantitative analytical methods real-time PCR for HER-2 gene quantification and ELISA of serum HER-2 protein and comparison with fluorescence in situ hybridization and immunohistochemistry for determining HER-2 status in breast cancer patients. Clin Chem 2005;51:1093-101.

8. Kindich R, Florl AR, Jung V, Engers R, Muller M, Schulz $W A$, et al. Application of a modified real-time PCR technique for relative gene copy number quantification to the determination of the relationship between NKX3.1 loss and MYC gain in prostate cancer. Clin Chem 2005; 51:649-52.

9. Crew KD, Neugut Al. Epidemiology of gastric cancer. World J Gastroenterol 2006;12:354-62.

10. Landis SH, Murray T, Bolden S, Wingo PA. Cancer statistics, 1998. CA Cancer J Clin 1998;48:6-29.

11. Aaltonen LA, Hamilton SR. Pathology and genetics of tumors of the digestive system. In: International Agency for Research on Cancer (IARC). World Health Organization Classification of Tumors. Lyon: IARC Press, 2000: 37-52.

12. American Joint Committee on Cancer. AJCC cancer staging manual, 6th ed. New York: Springer-Verlag, 2002:99-106.

13. Stroun M, Anker P, Maurice P, Lyautey J, Lederrey C, Beljanski M. Neoplastic characteristics of the DNA found in the plasma of cancer patients. Oncology 1989;46: 318-22.

14. Nawroz H, Koch W, Anker P, Stroun M, Sidransky D. Microsatellite alterations in serum DNA of head and neck cancer patients. Nat Med 1996;2:1035-7.

15. Castells A, Puig P, Mora J, Boadas J, Boix L, Urgell E, et al. K-ras mutations in DNA extracted from the plasma of patients with pancreatic carcinoma: diagnostic utility and prognostic significance. J Clin Oncol 1999;17:57884.

16. Usadel H, Brabender J, Danenberg KD, Jeronimo C, Harden S, Engles J, et al. Quantitative adenomatous polyposis coli promoter methylation analysis in tumor tissue, serum, and plasma DNA of patients with lung cancer. Cancer Res 2002;62:371-5.
17. Lo YM, Chan WY, Ng EK, Chan LY, Lai PB, Tam JS, et al. Circulating Epstein-Barr virus DNA in the serum of patients with gastric carcinoma. Clin Cancer Res 2001; 7:1856-9.

18. Gotoh T, Hosoi H, lehara T, Kuwahara Y, Osone S, Tsuchiya $\mathrm{K}$, et al. Prediction of MYCN amplification in neuroblastoma using serum DNA and real-time quantitative polymerase chain reaction. J Clin Oncol 2005;23:520510.

19. Lauren P. The two histological main types of gastric carcinoma: diffuse and so-called intestinal-type carcinoma. An attempt at a histo-clinical classification. Acta Pathol Microbiol Scand 1965;64:31-49.

20. Park JG, Frucht $H$, LaRocca RV, Bliss DP Jr, Kurita $Y$ Chen TR, et al. Characteristics of cell lines established from human gastric carcinoma. Cancer Res 1990;50: 2773-80.

21. Lee HS, Lee HK, Kim HS, Yang HK, Kim Yl, Kim WH. MUC1, MUC2, MUC5AC, and MUC6 expressions in gastric carcinomas: their roles as prognostic indicators. Cancer 2001;92:1427-34.

22. Corzo C, Corominas JM, Tusquets I, Salido M, Bellet M, Fabregat $\mathrm{X}$, et al. The MYC oncogene in breast cancer progression: from benign epithelium to invasive carcinoma. Cancer Genet Cytogenet 2006;165:151-6.

23. Mitsui F, Dobashi Y, Imoto I, Inazawa J, Kono K, Fujii H, et al. Non-incidental coamplification of Myc and ERBB2, and Myc and EGFR, in gastric adenocarcinomas. Mod Pathol 2007;20:622-31.

24. Livak KJ, Schmittgen TD. Analysis of relative gene expression data using real-time quantitative PCR and the $2^{-\Delta \Delta C T}$ method. Methods 2001;25:402-8.

25. Sai S, Ichikawa D, Tomita H, Ikoma D, Tani N, Ikoma H, et al. Quantification of plasma cell-free DNA in patients with gastric cancer. Anticancer Res 2007;27:2747-51.

26. Lee TL, Leung WK, Chan MW, Ng EK, Tong JH, Lo KW, et al. Detection of gene promoter hypermethylation in the tumor and serum of patients with gastric carcinoma. Clin Cancer Res 2002;8:1761-6.

27. Kim MA, Jung EJ, Lee HS, Lee HE, Jeon YK, Yang HK et al. Evaluation of HER-2 gene status in gastric carcinoma using immunohistochemistry, fluorescence in situ hybridization, and real-time quantitative polymerase chain reaction. Hum Pathol 2007;38:1386-93. 